\title{
Die Zähmung
}

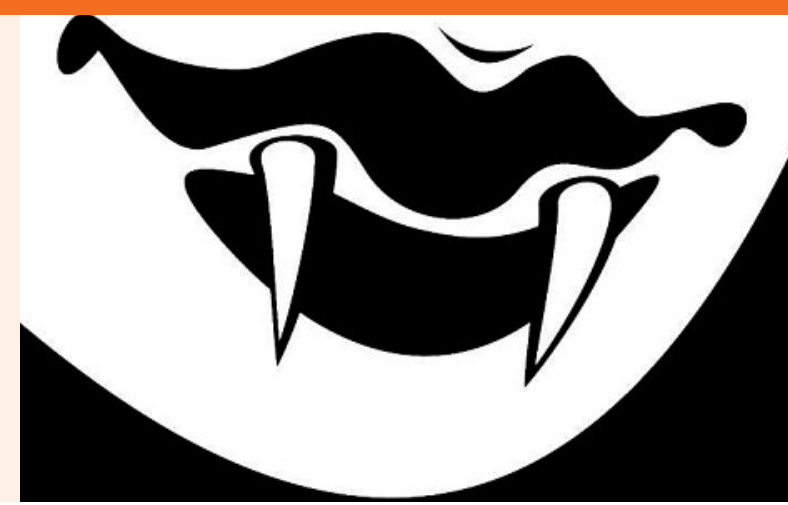

Erhard Taverna

erhard.taverna@saez.ch
In einem Anhang «The Principles of Newspeak» zum Roman «1984» erklärt George Orwell die Grundstruktur der offiziellen Sprache Ozeaniens. Das Projekt einer politisch gereinigten Sprache sah vor, das bisherige Englisch (Oldspeak) bis zum Jahre 2050 durch eine neue, parteikonforme Sprache (Newspeak) zu ersetzen. Die angestrebte, regimekonforme Ausrichtung sollte nebst einer vereinfachten Grammatik durch die Elimination unerwünschter Begriffe und einem Vokabular neuer, eindeutig festgelegter Wörter erreicht werden. Eine zentrale Sprachsäuberung sorgte für die stets kleiner werdende Wortwahl. In dieser Diktatur eine Lebensversicherung, denn je weniger Worte Newspeak zur Verfügung stellte, desto besser waren die Menschen vor den Versuchungen abweichenden Denkens geschützt.

Jede lebende Sprache ändert sich ständig, neue Wörter und neue Sprachbilder lösen die alten ab. Aber auch Sprachmanipulationen gehören zum Alltag. Wir kennen sie von der Werbung und der politischen Rhetorik. Weniger bekannt sind die Sprachfibeln für Journalistenverbände oder die zahlreichen Anpassungen und Veränderungen literarischer Texte, die meist in bester Absicht, aus religiösen oder pädagogischen Gründen, Ersatzbegriffe einführen oder Wörter ächten. Je beliebter Kinderbücher sind, desto mehr sind sie umstritten. Grimms Märchen sind zu grausam für unsere Kleinen, 1001-Nacht-Geschichten zu anstössig, der Struwwelpeter brutal und rassistisch, Zehn kleine Negerlein, Hatschi Bratschis Luftballon oder Max und Moritz sind definitiv Oldspeak. Wer die eigenen Kinderbücher mit den späteren Auflagen für die Generation der Kinder und Enkel vergleicht, findet interessante Textunterschiede. Exemplarisch dafür ist die beliebte Romanserie «Fünf Freunde» der englischen Autorin Enid Blyton. Das seit den 40er und 50er Jahren millionenfach verkaufte Original ist in den 80ern nach anstössigen Stellen durchforscht und korrigiert worden. Um das Kinderzimmer vor den Vorstellungen einer Ewiggestrigen zu beschützen, wurde die Autorin posthum umerzogen, die Texte von Mobbing und rassistischen oder sexis- tischen Darstellungen gereinigt, schwarz-weiss zugespitzte Gegensätze weichgezeichnet. Worte wie Tramp und Zigeuner sind ersetzt, Szenen, die angeblich Rollenklischees verbreiten, sind umformuliert, Namen abgeändert, körperliche Gewalt, wie zum Beispiel eine Ohrfeige, durch mahnende Worte ersetzt. Die Sprachpolizei hat selbst bei Lafontaines Fabelübersetzung Alarm geschlagen. Wenn aus dem französisch-maskulinen «corbeau» eine deutsch-feminine «Krähe» wird, schafft das Probleme. Denn der Käse im Schnabel, den der Fuchs listig erbeutet, entspricht für die Moralhüter dem Cliché der dummen, eitlen Frau, die sich vom schlauen Mann übertölpeln lässt. Ein schwieriger Fall. Der Geschlechterkampf verändert die englische Umgangssprache. Landlady und landlord verkümmern zum owner, mother- und fatherland zum native land, steward und stewardess sind flight attendants, das gentleman agreement weicht dem informal agreement. Aber auch Ärztinnen und Ärzte sind Medizinalpersonen oder verschwinden ganz im juristischen Eintopf der Gesundheitsberufe. Geschichtsbücher werden politisch korrekt neu verfasst, Wandgemälde an öffentlichen Gebäuden, die überholte Auffassungen darstellen, zeitgemäss übermalt. Neuübersetzungen originalsprachlicher Bibeltexte führen zu neuen Interpretationen. Die Schriften in «geschlechtergerechter» Sprache, das veränderte historische Verständnis und die Betonung sozialer Gerechtigkeit sollen tradierte, patriarchale Denkformen beseitigen.

Biblisch begründet war der erfolgreiche Kampf gegen die Kitsch- und Schundliteratur. Früh schon hatten die Puritaner Walt Disneys Mickey Mouse gezähmt. Denn die Maus war anfangs ein Rüpel und Wüstling, der 1928 in seinem allerersten Abenteuerfilm «Plane Crazy» Tiere quälte und Minnie sexuell belästigte. Lustvoll aggressiv konnte er auch besoffen über die Leinwand torkeln. Erst die Sittenwächter und der Erfolg machten ihn zum heutigen Allerweltslogo, niedlich, plüschig und schwanzlos. Carl Barks hatte 1942 einen jähzornigen, gewalttätigen Donald Duck samt Entenhausener Universum 
erschaffen. Doch auch der Geflügelmaler musste schnell Konzessionen machen, Entenbrüste einebnen und in den 50er Jahren auf attraktive Menschenfrauen verzichten. In Hitlerdeutschland verboten, in den 70er Jahren als faschistoider Kleinbürger beschimpft, ist der Schnatteri, wie er anfangs in der Schweiz hiess, trotz aller Zensur zum Weltstar geworden. Nur das onkelhaft-asexuelle Fortpflanzungsverhalten der DuckSippe ist bis heute ein ungelöstes und damit toleriertes Rätsel geblieben. Ähnliches liesse sich über den blauen Papagei mit der rot-schwarz karierten Hose und der Baskenmütze erzählen. In der Wirtschaftskrise der 30er vom Maler Robert Lips als Werbefigur entworfen, wurde Globi zur popu- lären Kinderbuchfigur. Auch er, anfangs noch ziemlich frech und aufsässig gegenüber Respektspersonen, musste 1940 als Soldat einrücken und geistige Landesverteidigung betreiben. Da er seit den 80er Jahren keine Wutanfälle mehr hat und niemanden nervt, ist ihm Ritalin erspart geblieben. Heute ein sanfter, manierlicher Vogel, unterrichtet er die Kinder, pädagogisch vorbildlich, im Tier- und Umweltschutz.

Es gibt für Newspeak immer noch sehr viel zu tun. Unzählige Bücher müssten gereinigt und desinfiziert werden, bis sie alle wie die jüngsten Vampirfilme aus den USA daherkommen: nett, hilfsbereit, enthaltsam, aseptisch und langweilig.

\section{Zum holistischen Weltbild*}

\section{Hans Koblet}

\footnotetext{
* Ein Versuch im Zusammenhang mit dem Artikel von Prof. Dr. Martin Lambeck: Fehldeutungen der Physik und Philosophie in der Alternativmedizin [1].
}

Es geht hier keineswegs um eine Kritik am genannten Artikel, den ich mit Genuss und $\mathrm{Zu}-$ stimmung gelesen habe. Ein holistisches Weltbild aufgrund der Quantenphysik und des EPR erscheint auch mir (als Nichtphysiker) unhaltbar. Es geht mir aber darum, dass man aufgrund völlig anderer Überlegungen das Universum als ganzheitlich betrachten kann, in dem «alles mit allem zusammenhängt». Diese Überlegungen sind einfach, materialistisch und lauten wie folgt:

1. Protonen sind keiner bekannten Halbwertszeit unterworfen. Sie sind mit der Schaffung der Elementarpartikel nach dem Urknall entstanden. Deshalb ist alles, woraus ich in jedem Augenblick bestehe, durch jedwelche Form des Lebens seit der Entstehung des Lebens auf diesem Planeten hindurchgeflossen, auch durch Tiere und Pflanzen, die längst gestorben oder ausgestorben sind. Ich betrachte das als die kosmische vertikale Verknüpfung.

2. Tiere und Menschen leben von Lebendigem; Menschen, Tiere und Pflanzen sind den Gesetzen der Thermodynamik unterworfen. Wir bauen die Nahrungsstoffe ab, auf und um, so wie die genetischen Bauanleitungen dies festsetzen. Die ausgeschiedenen Reste gehen wieder in Lebendiges ein. Wir sterben gleichsam ununterbrochen und werden wieder geboren, so lange wir leben. Auch unsere Leichen gehen direkt oder indirekt zurück, werden ab-, aufund umgebaut und treten ein in vielfältiges, unbekanntes Leben. Ich betrachte das als eine kurzfristige horizontale Verknüpfung.

3. Der Tod ist somit nur ein vorübergehendes Ende eines kontinuierlichen Vorganges. Unser aller Tod ist eine unabdingbare Notwendigkeit, da die Erde ein weitgehend geschlossenes System ist. Was sie von aussen erhält, ist Energie und vielleicht etwas Wasser und Gestein, aber sie lebt vom Tod. Ich betrachte das als eine langfristige Verknüpfung in der Horizontalen und in der Vertikalen.

4. Nach allem, was wir wissen, ist vor Urzeiten Leben nur ein oder wenige Male entstanden. In beinahe vier Milliarden Jahren hat sich das Leben diversifiziert; Arten sind aufgetreten und wieder verschwunden in einem Kontinuum des Werdens und Vergehens. Somit sind wir alle untereinander verwandt. Der Mensch ist ein Produkt eines kambrischen Bauplanes mit einem Skelett und trägt in seiner Konstruktion noch Relikte seiner Vorfahren im Wasser. Die Annahme, wonach Wirbeltiere wie auch der Mensch zwar über ähnliche Baupläne mit Lebern, Lungen, Muskeln, Gehirn usw. wie auch über eine weitgehend gleiche Biochemie verfügen, dass aber im geistigen, seelischen und im Verhaltensbereich ein unüberwindlicher Hiatus zwischen Mensch und Tieren bestünde, halte ich für grössenwahnsinnig. Die Evolution arbeitet nicht so; sie beruht mehrheitlich auf einem Kontinuum, das aufgrund von Vorbestehendem Variationen erzeugt, die erfolgreiche Eigenschaften bewahren, sei das nun in der Leber oder im Gehirn. Die Verwandtschaft wird auch erhärtet durch molekularbiologische und neurophysiologische Untersuchungen, die zeigen, wie lange viele Gene und Strukturen fast unverändert in der Lebe- 
welt bewahrt werden. Die Verhaltensforschung zeugt von ähnlichen Erscheinungen. Darwin kannte die Mechanismen, mit der Variationen zustande kommen, noch nicht. Heute kennen wir sie.

Eine «Urzeugung» gibt es nicht mehr, denn wo Leben war und ist, sind auch Enzyme vorhanden, die neu entstandene Moleküle mit informatorischen Eigenschaften (an sich eine unwahrschein-

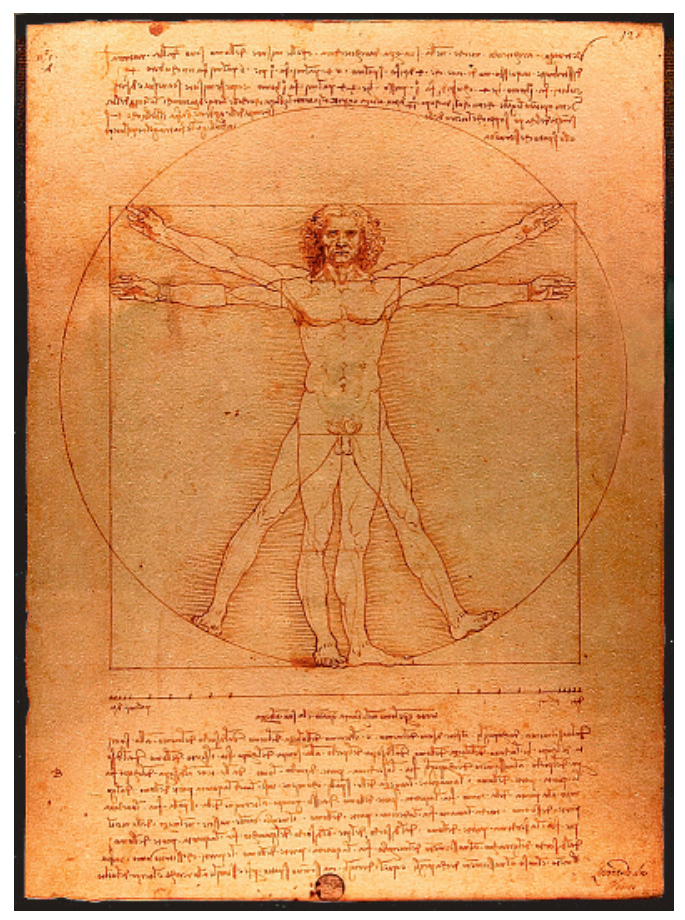

«Proportionsschema der menschlichen Gestalt nach Vitruv» von Leonardo da Vinci (1485/90, Venedig, Galleria dell'Accademia). liche Möglichkeit) abbauen würden. Punkt 4 betrachte ich als die langfristige irdische Vertikale.

Die mystische Verbindung zu Gott lasse ich beiseite und beschränke mich auf Überlegungen, die Resultate von gesichertem Wissen sind. Sie zeigen horizontale und vertikale Verknüpfungen, die wunderbar genug sind, um ein holistisches Weltbild zu vertreten, sofern eben die Zeit mit berücksichtigt wird. Vielen mag es trotzdem in seinem nackten Materialismus zu dürftig sein. Wahrscheinlich ist es auch nicht neu. Heraklits «Alles fliesst» geht in dieser Richtung. In etwas anderem Sinne hat Friedrich von Logau (16041655) geschrieben: «Der Tod ist unser Vater, von dem uns neu empfängt / Das Erdgrab, unser Mutter, und uns in ihr vermengt; / Wann nun der Tag wird kummen, und da wird sein die Zeit, / Gebiert uns diese Mutter zur Welt der Ewigkeit.» Und Theodor Storm hat gedichtet: ... «Denn was wir Leib und Seele nennen, / So fest in eins gestaltet kaum, / Er löst sich auf in tausend Teilchen / Und wimmelt durch den öden Raum. // Es waltet stets dasselbe Leben, / Natur geht ihren ew'gen Lauf; / In tausend neuerschaffnen Wesen / Stehn diese tausend Teilchen auf. // Das Wesen aber ist verloren, / Das nur durch ihren Bund bestand, / Wenn nicht der Zufall die verstäubten / Aufs neu zu einem Sein verband.» Oder Rabindranath Tagore: "Alles Wachsen ist ein Sterben, / Jedes Werden ein Vergehen. / Alles Lassen ein Erleben, / Jeder Tod ein Auferstehen.»

1 Lambeck M. Fehldeutungen der Physik und Philosophie in der Alternativmedizin. Schweiz Ärztezeitung. 2008;89(50):2186-9. 